\title{
Article
}

\section{Noises in Double-Differenced GNSS Observations}

\author{
Dominik Prochniewicz $^{1}$ (D) , Jacek Kudrys ${ }^{2,3}$ and Kamil Maciuk ${ }^{2,3, *(\mathbb{D})}$
}

1 Faculty of Geodesy and Cartography, Warsaw University of Technology, 00-661 Warsaw, Poland; dominik.prochniewicz@pw.edu.pl

2 Department of Integrated Geodesy and Cartography, AGH University of Science and Technology, 30-059 Krakow, Poland; jkudrys@agh.edu.pl

3 Joint International Tourism College, Hainan University—Arizona State University, Haikou 570228, China

* Correspondence: maciuk@agh.edu.pl

check for updates

Citation: Prochniewicz, D.; Kudrys,

J.; Maciuk, K. Noises in

Double-Differenced GNSS

Observations. Energies 2022, 15, 1668

https://doi.org/10.3390/en15051668

Academic Editors: Karolina

Krzykowska-Piotrowska,

Fengshou Gu and Wei-Hsin Chen

Received: 3 December 2021

Accepted: 18 February 2022

Published: 23 February 2022

Publisher's Note: MDPI stays neutral with regard to jurisdictional claims in published maps and institutional affiliations.

Copyright: (C) 2022 by the authors. Licensee MDPI, Basel, Switzerland. This article is an open access article distributed under the terms and conditions of the Creative Commons Attribution (CC BY) license (https:// creativecommons.org/licenses/by/ $4.0 /)$.

\begin{abstract}
Precise data processing from the Global Navigation Satellite Systems (GNSS) reference station network is mainly based on a combination of double-differenced carrier phase and code observations. This approach allows most of the measurement errors to be removed or reduced and is characterized as the most accurate method. However, creating observation differences between two receivers and two satellites increases the measurement noise of the observations by a factor of 2 . As a result, it increases the impact of the incorrect definition of the noise characteristic on the results of the estimation of the unknowns in the positioning model. This is especially important in Multi-GNSS solutions, which integrate measurements from different systems, for which the stochastic parameters of observation may differ significantly. In this paper, the authors prepared a complex analysis of the noise type in double-differenced GNSS (GPS, GLONASS and Galileo) observations, both carrier phase and code ones, with a $1 \mathrm{~s}$ sampling interval. The Autocorrelation Function (ACF) method, the Lomb-Scargle (L-S) periodogram method, and the Allan variance (AVAR) method were used. The results that were obtained for the weekly set of measurement data showed that, depending on the system and type of observation, the noise level and its type are significantly different. Among the code measurements, the lowest noise levels were obtained for the GPS C5Q and Galileo C7Q/C8Q observations, with the standard deviations not exceeding $\pm 10 \mathrm{~cm}$, while the noisiest observations were for the GLONASS C1C and C2C signals, which had standard deviations of about $\pm 90 \mathrm{~cm}$ and $\pm 45 \mathrm{~cm}$, respectively. For the carrier phase observations, each signal type was characterized by very similar noise levels of $\pm 1.5-3.5 \mathrm{~mm}$. The ACF analysis showed that $1 \mathrm{~Hz}$ double-differenced GNSS data can only be treated as being not correlated to time for carrier phase observations; for code observations, an irrelevant autocorrelation may be considered for measurement intervals greater than $20 \mathrm{~s}$. Depending on the GNSS signals, the spectral index $\mathrm{k}$ varies in a range from -1.3 to -0.2 for code data and $\mathrm{k}=0.0$ in the case of phase data. Using the modified Allan deviation (MDEV) allows for specific noise types for each signal and GNSS system to be determined. All of the code observations were characterized by either flicker PM or white PM. In the case of the phase observations, they were all uniquely characterized by white PM (GPS and Galileo or by white PM and flicker PM (GLONASS).
\end{abstract}

Keywords: GNSS; observations noise; double-difference; code; carrier phase

\section{Introduction}

Global Navigation Satellite Systems (GNSS) measurements, similar to all other observation measurements, are affected by noise. The correct processing of measurement data requires considering the random nature of the noise in the stochastic model of the observations. The most common assumption for Global Positioning System (GPS) data processing is to adopt a constant noise characteristic that does not change over time [1]. Accordingly, GPS observation noise is commonly assumed to be a stationary random process. In practice, most GPS data processing models consider observation noise as easy-to-implement white noise, i.e., a random process with samples that are not correlated in time with a zero mean 
and diagonal variance-covariance (VC) matrix. For this type of noise, the signal power spectrum is equal in all frequency bands. Identifying the type of noise allows for the determination of the noise density coefficients that are characteristic of a given noise, which can be included in the mathematical model of the observation development through the stochastic model [2,3]. Moreover, the noise is one of the coefficients that, in Kalman filtering for example, makes it possible to increase the accuracy of the position determination $[4,5]$.

Adopting the white noise assumption for GPS observations is not a strict approach. Analyses of code and carrier phase measurements have shown significant temporal correlation, mainly due to the atmospheric delay, multipath effect, and the receiver itself [6-8] as well as cross-correlations between different types of observation [9-11]. The obtained correlation parameters were dependent on the type of observation and the measurement set. Non-uniformity in observation noise parameters that is even more significant occurs when comparing Multi-GNSS measurements. The different characteristics of the measurement noise for the GPS, GLONASS, Galileo, and BeiDou systems [12] as well as for individual blocks of satellites within a given system [13] make the development of a stochastic model for a multi-system solution difficult and complex.

The existing stochastic models for GNSS observations mainly use the dependence of observation variance in the satellite elevation [14-16], Signal-to-Noise (SNR) [17,18], and Carrier-to-Noise density Ratio (C/N0) [19-21] parameters as well as others parameters: the ionosphere scintillation [22], receiver tracking error [23], or multipath effect [24]. However, these models do not take into account the characteristics of the type of observation noise and only describe its dependence on selected parameters. In this work, an attempt was made to perform a multidimensional analysis of the GNSS measurement noise, the aim of which was to fully describe the stochastic parameters of individual types of observations. In particular, different types of carrier phase and code observations for the GPS, GLONASS, and Galileo systems were analyzed. The analysis of the measurement noise characteristics was performed with the use of three statistical tools: the autocorrelation function (ACF), the Lomb-Scargle (L-S) periodogram method, and the Allan variance (AVAR) method. These data analysis tools allow noise-type observations to be studied and do not include an analysis of the dependence of the noise level on SNR, C/N0, satellite elevation, and receiver type, which may be part of the further studies that take all of these factors into account.

The ACF is a well-known analytical measure for time-domain signals, which plays a significant role in the time series models for the identification and evaluation of the correlation degree. In statistics, the autocorrelation of random processes is the Pearson correlation coefficient between the time series and its copy shifted by the time lag, which is expressed as a function of the delay. The ACF is defined for stationary processes, but in practice, it is often used, even if the data do not meet the stationarity conditions [25]. In this study of the time series for the GNSS measurements time series, the ACF is used to determine the parameters of the temporal correlation of observations, which, in the form of empirical models (e.g., exponential function [26]), is applied to the stochastic model of the data. Analyses of the residuals of double-differenced carrier phase GPS observations show the existence of significant temporal correlations for both medium-long and zeroshort baselines $[27,28]$. The obtained time correlation values differ significantly for a given measurement set; however, the time correlation is clearly dependent on the measurement interval data recorded at a higher frequency and that are more time-correlated.

In many types of time series of natural phenomena, noise can be described by a power-law noise process [29]. This kind of noise has been identified in, e.g., music [30], economics [31], geophysical data [32], electronic devices [33], astronomy [34], and GNSS positions [35]. There are several ways to determine this kind of noise, most of which are based on spectral analyses or maximum likelihood estimation [32,36]. A commonly used approach for power-law noise identification is to calculate the power spectrum of the data and then estimate the spectral index using linear regression [29] from the log-log plot of the spectrum. The slope of the fitted straight line corresponds to the kind of noise in the analyzed data. To estimate the power spectrum of unevenly sampled data or data 
with gaps, such as in our case, the Lomb-Scargle periodogram method is particularly useful $[37,38]$.

AVAR was originally invented to analyze the stability of atomic clocks in the 1960s [39]. Standard variance measures the total signal power, and it does not allow for the signal stability to be characterized, which is in contrast to Allan variance. Currently, it is also used to analyze various types of phenomena in astrometry or geodynamics $[40,41]$ in addition to tools such as the autocorrelation function or spectral densities [42]. The most common geodetic usage is the analysis of the geodetic time series. This has been used to determine the uncertainties associated with site positions [43]. Moreover, AVAR is resistant to data gaps up to 50\% [44]. The greatest advantage, apart from simplicity and speed, of AVAR is that it also allows for the noise type and level to be characterized without any a priori model assumptions [45]. An Allan graph in a log-log scale shows the relationship between the Allan variance and the sampling time in terms of its error spectrum, where slopes of the graphs represent noise, e.g., slope -1 is white noise, while a slope of 0 is flicker noise [46].

The paper is organized as follows: In Section 2, we present the materials data analysis methods used; in particular, the zero-baseline double-differenced GNSS observables are characterized, and the mathematical foundations of the $\mathrm{ACF}$, the spectral analysis using the L-S method, and AVAR are outlined. In Section 3, the data set and statistical analysis of the GPS, GLONASS, and Galileo codes and the carrier phase observations are presented. In Section 4 , the results of the noise analysis that was performed based on different statistical tools are described in detail. Finally, in Section 5, a discussion is conducted, and concluding remarks are made.

\section{Materials and Methods}

\subsection{Zero-Baseline Double-Differenced Observable}

The noise parameters of the GNSS observations were derived using double-differenced (DD) measurements from a zero-length baseline (ZB) carried out by two receivers of the same type. The ZB DD observation combination effectively separates the measurement noise from the deterministic portion (e.g., atmospheric delays, clock and orbital errors, multipath effects) and does not de-correlate the time series, which is essential for autocorrelation analysis.

The simplified code $(\mathrm{P})$ and carrier phase $(\mathrm{L})$ observation equations are represented by the following formulas:

$$
\begin{gathered}
P=R+c \delta t+\delta T+\delta I+\delta M_{P}+\delta K_{P}+\varepsilon_{P} \\
L=R+c \delta t+\delta T-\delta I+\delta M_{L}+\delta K_{L}+\lambda B+\varepsilon_{L}
\end{gathered}
$$

where $R$ is the geometric distance of the satellite receiver (including the satellite orbital errors, antenna phase centre offset for the satellite, and receiver as well as carrier phase wind-up errors), $\delta t$ denotes the difference in the receivers satellite clock error, $\delta T$ and $\delta I$ denote the troposphere and ionosphere errors, $\delta M_{P}$ and $\delta M_{L}$ are the multipath effects for code and carrier phase, respectively, $\delta K_{P}$ and $\delta K_{L}$ denote differences in the receiver satellite hardware biases for the code and carrier phase observations, $B$ is the integer for carrier phase ambiguity, and $\varepsilon_{P}$ and $\varepsilon_{L}$ are random errors for the code and carrier phase measurements. All of the parameters are expressed in units of length, except for the clock errors, which are expressed in units of time, and the integer carrier phase ambiguity, which is denoted in wave cycles. Additionally, $c$ and $\lambda$ denote the speed of light and carrier wavelength, respectively.

The ZB DD combinations are computed by differencing each type of observation (for the same frequency/signal type) from the two receivers connected to the same antenna to the two satellites during the same measurement epoch. For such a combination, all of the geometrical parameters are eliminated, except for the double-differenced (denoted by the symbol $\nabla \Delta$ ) carrier phase ambiguity parameter, which can be easily resolved if the precise coordinates of the antenna are known. The ZB DD observables for the code $(\nabla \Delta P)$ 
and carrier phase $(\nabla \Delta L)$ (after subtracting the DD carrier phase ambiguity) only contain the double-differenced measurement noise, which expresses the magnitude of the random errors in the observed signal. Assuming that the combinations are only computed for intrasystem differences and that the inter-frequency bias (IFB) is eliminated for the GLONASS system because it uses Frequency Division Multiple Access (FDMA), the expectation $(E\{\Delta\})$ and the dispersion $(D\{\Delta\})$ of the ZB DD combination for a pair of homogeneous receivers can be expressed as the equations [47]:

$$
\begin{gathered}
E\{\nabla \Delta L\}=0 \\
D\{\nabla \Delta L\}=4\left(1-\rho_{\Delta}\right) \sigma_{L}^{2}
\end{gathered}
$$

ZB DD dispersion describes the measurement noise with a variance $\sigma_{L}^{2}$, which is affected by the cross-correlation $\rho_{\Delta}$ due to the simultaneous use of the same antenna (in a zero-length baseline setup) with a common Low-Noise Amplifier (LNA) [48,49]. Observation differencing eliminates common LNA noise in the ZB DD time series, causing the dispersion value to be significantly reduced. However, when assuming a constant LNA noise value over time, $\rho_{\Delta}$ does not affect the determined noise parameters. The equations relate to the carrier phase observations, but they have an analogous form with the parameter $\sigma_{P^{-}}$, which is used for code observations.

\subsection{Autocorrelation Function}

The time correlation of the observation time series was determined by the ACF, which measures the correlation between the $x(t)$ and $x(t+\tau)$ of the $x(t)$ stochastic process expressed by [1]:

$$
\sigma^{2}(\tau)=\frac{1}{T} \sum_{t=1}^{T-\tau}[x(t)-\bar{x}][x(t+\tau)-\bar{x}]
$$

where $\sigma^{2}(\tau)$ expresses the time series $x(t)$ of the sample covariance with the same series shifted at time lag $\tau, \bar{x}$ is the mean of $x$, and T denotes the effective sample size for time series $\mathrm{x}$. The time correlation coefficient $\rho_{t}(\tau)$ for lag $\tau$ can be determined as:

$$
\rho_{t}(\tau)=\frac{\sigma^{2}(\tau)}{\sigma_{0}^{2}}
$$

where $\sigma_{0}^{2}$ is a simple variance of $x(t)$ for $\tau=0$.

If the considered time series is affected by purely random noise, then the time correlation coefficient takes the values

$$
\rho_{t}(\tau)= \begin{cases}1 & \tau=0 \\ 0 & \tau \neq 0\end{cases}
$$

Otherwise, the time series can be described as an autoregressive (AR) model.

\subsection{Spectral Analysis}

For the purposes of this paper, the L-S periodogram method was used for spectral analysis and to estimate the type of noise present in the DD data. This method has particularly broad applications in astronomy and geodynamics and allows the frequency spectrum to be calculated for non-uniformly sampled or intermittently sampled data. The gaps in the analyzed DD time series are mainly due to the signal blocking caused by the horizon obscuration for low satellites. On the other hand, during the formation of double differences, the reference satellite DDs are not calculated. This results in there being gaps in the days of several tens of minutes.

The power spectrum of various natural phenomena can be approximated by the power-law rule: 


$$
P(f) \propto f^{k}
$$

where $P$ is a power spectrum, $f$ is the signal frequency, and $k$ is the spectral index. The spectral index value corresponds to specific noise in the analyzed signal. White noise is $k=0$, flicker noise (pink noise) is $k=-1$, and random walk is $k=-2$ [49]. Noises with a fractional spectral index within the range $-3<k<-1$ are called "fractional random walk" or "fractional Brownian motions" and are typical of nonstationary processes. Stationary processes with $-1<k<1$ are called "fractional white noise" or "fractional Gaussian" [35]. The value of $\mathrm{k}$ can be calculated as the slope of a straight line fitted in the power spectrum after the transformation of frequency and power to the logarithmic scale. This simple method of estimating the spectral index $k$ produces satisfactory results, especially for large time series lengths [29].

\subsection{Allan Variance}

AVAR and its modifications represent another analysis tool. AVAR is used to compare time series and their internal noise through the calculation of the deviation for a discrete set of different averaging times $(T)$. AVAR (and its related variance) and noise identification are calculated based on the set of $N$ discrete $x_{i}$ data for $i=1,2, \ldots, N-1$, which are converted into the fractional frequency, $y_{i}$ :

$$
y_{i}=\frac{x_{i+1}-x_{i}}{T}
$$

where $T$ is the averaging time between two adjacent sets of observation data, $x_{i+1}$ and $x_{i}$. AVAR is defined as [50]:

$$
\sigma_{y}^{2}(T)=\frac{1}{2(M-1)} \sum_{i=1}^{M-1}\left[y_{i+1}-y_{i}\right]^{2}
$$

where $M$ is the frequency measurements for the averaged time $T=m T_{0}, m$ is the averaging factor, and $\tau_{0}$ is the basic measurement interval. $M$ is the number of fractional frequencies averaged over the sampling interval T. In terms of the GNSS phase data, AVAR may also be calculated as a combination of Equations 6 and 7, which can be expressed as:

$$
\sigma_{y}^{2}(T)=\frac{1}{2(N-2) T^{2}} \sum_{i=1}^{N-2}\left[x_{i+2}-2 x_{i+1}+x_{i}\right]^{2}
$$

The results are usually as the square root, $\sigma_{y}(T)$, i.e., the ADEV.

In this paper, a modified version of the ADEV called the modified Allan deviation (MDEV) was used [51,52]:

$$
\operatorname{Mod}_{y}^{2}(T)=\frac{1}{2 m^{2} T^{2}(N-3 m+1)} \sum_{j=1}^{N-3 m+1}\left\{\sum_{i=j}^{j+m-1}\left[x_{i+2 m}-2 x_{i+m}+x_{i}\right]\right\}^{2}
$$

where $x_{i}$ is the $i$ th of the $N=M+1$ phase values for the average time $T$. Compared to other Allan deviation modifications, $M D E V$ allows white $(\mathrm{W})$ and (F) flicker phase modulation (PM) noise to be distinguished from each other. The W and F PM noise slopes are both close to -1 when using Allan deviation, but the modified Allan deviation separates them to -1.5 and -1.0 , respectively [53].

\section{Data Description}

The ZB DD observation combinations were derived using the GNSS measurements from reference station WUT1, which is situated on the roof of the Main Building of the Warsaw University of Technology (approx. location: $52^{\circ} 13^{\prime} 15^{\prime \prime} \mathrm{N}, 21^{\circ} 00^{\prime} 37^{\prime \prime} \mathrm{E}$, see Figure 1). The Multi-GNSS measurements from the GPS, GLONASS, and Galileo systems, including the code and carrier phase observations on the L1, L2 and L5 bands, were carried out for the 
$0^{\circ}$ elevation mask and $1 \mathrm{~Hz}$ interval using two identical Trimble $\mathrm{R} 9 \mathrm{~s}$ receivers connected to a single Leica Choke-Ring AT504 antenna through a GNSS signal splitter.

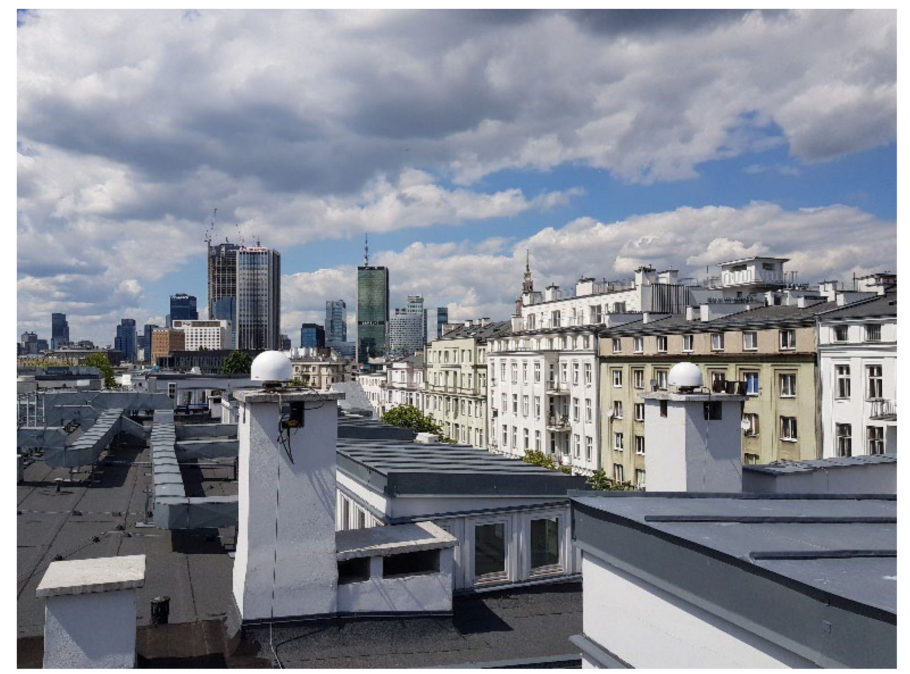

Figure 1. GNSS reference stations on the roof of the Main Building of the Warsaw University of Technology-WUT1 station on the right side.

The observations covered seven subsequent daily sessions for the year 2019, DOY: 055-061. A detailed description of the observed signals is presented in Table 1.

Table 1. Types of the observations used for the analysis for each GNSS system (notation according to RINEX 3.04 format [54].

\begin{tabular}{cccc}
\hline $\begin{array}{c}\text { System/ } \\
\text { Observation Type }\end{array}$ & L1 & L2 & L5 \\
\hline GPS & C1C/L1C & C2L/L2L C2W/L2W & C5Q/L2Q \\
\hline GLONASS & C1C/L1C C1P/L1P & C2C/L2C C2P/L2P & \\
\hline Galileo & C1C/L1C & & C5Q/L5Q C7Q/L7Q C8Q/L8Q \\
\hline
\end{tabular}

The noise parameters of the individual GNSS observations were determined based on the ZB DD combination during a daily regime, obtaining seven independent sets of results. The mean values for the weekly solution were presented as the final values of the derived variance, autocorrelation, modified Allan deviation, and spectral indexes based on the linear regression of the Lomb-Scargle periodograms.

Figures 2 and 3 present the noise statistics for one daily solution (2019, DOY:055) for the code and carrier phase observations for all of the satellites. The results are presented using a box plot, where the median is indicated as a central mark in the box, and the 75th and 25th percentiles of the errors are marked as the top and bottom edges of the box, respectively. The whiskers indicate the most extreme values, omitting outliers with a confidence level of about $99 \%$. 


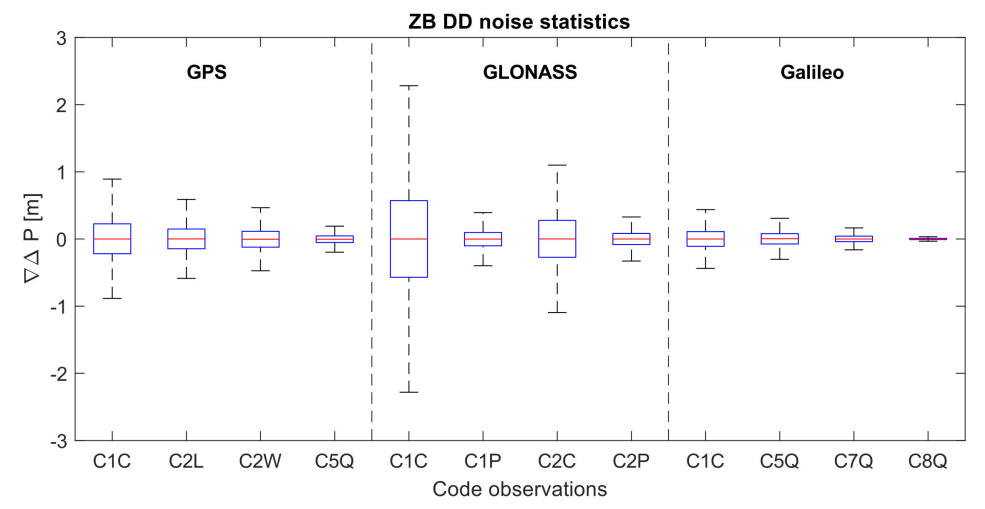

Figure 2. ZB DD time series noise statistic for code observations (2019 DOY:055).

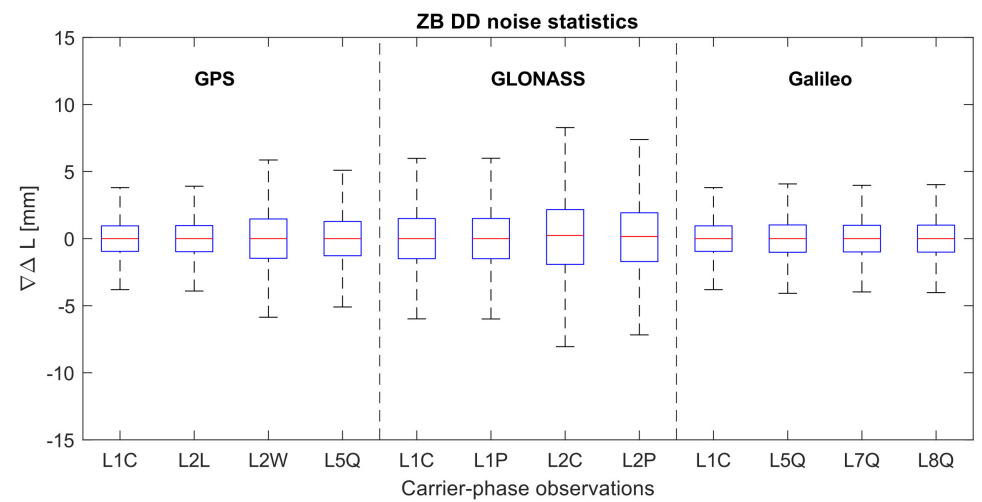

Figure 3. ZB DD time series noise statistic for carrier phase observations (2019 DOY:055).

The statistics for the mean weekly solution are presented in Table 2. The results show that there is a large amount of variation in the measurement noise level depending on the GNSS system and type of observation. For the code measurements, the GLONASS $\mathrm{C} 1 \mathrm{C}$ and $\mathrm{C} 2 \mathrm{C}$ signals are characterized by the highest noise, with standard deviations of $\pm 0.89 \mathrm{~m}$ and $\pm 0.44 \mathrm{~m}$, respectively. On the other hand, the Galileo C7Q and C8Q and GPS C5Q observations have the lowest noise level, not exceeding $\pm 0.10 \mathrm{~m}$. For the carrier phase measurements, the variability is smaller, and the noise level ranges from $\pm 1.5 \mathrm{~mm}$ for the GPS L1C and Galileo L1C observations to $\pm 3 \mathrm{~mm}$ for the GPS L2W and GLONASS L2C observations. For all of the observations, the mean value is very close to zero. However, it should be remembered that the presented standard deviation values refer to the doubledifferenced observations, which are increased in relation to the undifferenced observations by a factor of 2 and decreased by the common antenna LNA noise for the zero-length baseline configuration.

The repeatability for the mean obtained from processing of the seven daily sessions did not exceed $\pm 3 \mathrm{~mm}$ for the code observations of $\pm 0.001 \mathrm{~mm}$ for the carrier phase observations, proving that the consistency of the daily solution is very high. A lower weekly repeatability at the level of $\pm 0.08 \mathrm{~mm}$ was only obtained for the GLONASS carrier phase L2C and L2P observations. For the standard deviations, a similar very high repeatabilities of $\pm 5 \mathrm{~mm}$ and $\pm 0.03 \mathrm{~mm}$ for the code and carrier phase observations were obtained, with the exception of the GLONASS observations, for which the value of $\pm 8 \mathrm{~mm}$ was determined for $\mathrm{C} 1 \mathrm{C}$ and $\mathrm{C} 2 \mathrm{C}$. 
Table 2. Statistics for ZB DD code and carrier phase noise for the weekly solution.

\begin{tabular}{cccccc}
\hline \multirow{2}{*}{ System/Observation Type } & \multicolumn{2}{c}{ Code (m) } & \multicolumn{2}{c}{ Phase (mm) } \\
\cline { 2 - 5 } & & Mean & Std. & Mean & Std. \\
\hline \multirow{3}{*}{ GPS } & 1C & 0.002 & \pm 0.370 & 0.00 & \pm 1.50 \\
& 2L & -0.001 & \pm 0.243 & 0.00 & \pm 1.69 \\
& 2W & -0.002 & \pm 0.229 & 0.00 & \pm 3.41 \\
GLONASS & 5Q & -0.001 & \pm 0.095 & 0.00 & \pm 1.95 \\
\hline \multirow{5}{*}{ Galileo } & 1C & 0.001 & \pm 0.891 & 0.00 & \pm 2.41 \\
& 1P & -0.002 & \pm 0.151 & 0.00 & \pm 2.50 \\
& 2C & 0.002 & \pm 0.444 & 0.03 & \pm 3.03 \\
& 2P & -0.001 & \pm 0.133 & 0.01 & \pm 2.92 \\
\hline
\end{tabular}

\section{Results}

\subsection{Autocorrelation Function}

The ACF was determined to be able to find a temporal correlation in the ZB DD time series. Figures 4-6 present examples from one daily solution (2019 DOY:055) sample autocorrelation coefficient for all of the analyzed GNSS signals calculated as an average for all satellites. Each plot shows the ACF for a 0-3600 sec time lag and an enlarged function curve for the time lag range $0-60 \mathrm{~s}$ for the code and $0-30 \mathrm{~s}$ for the carrier phase observations. Additionally, the $\rho_{t}$ values for selected $\tau$ values are listed.
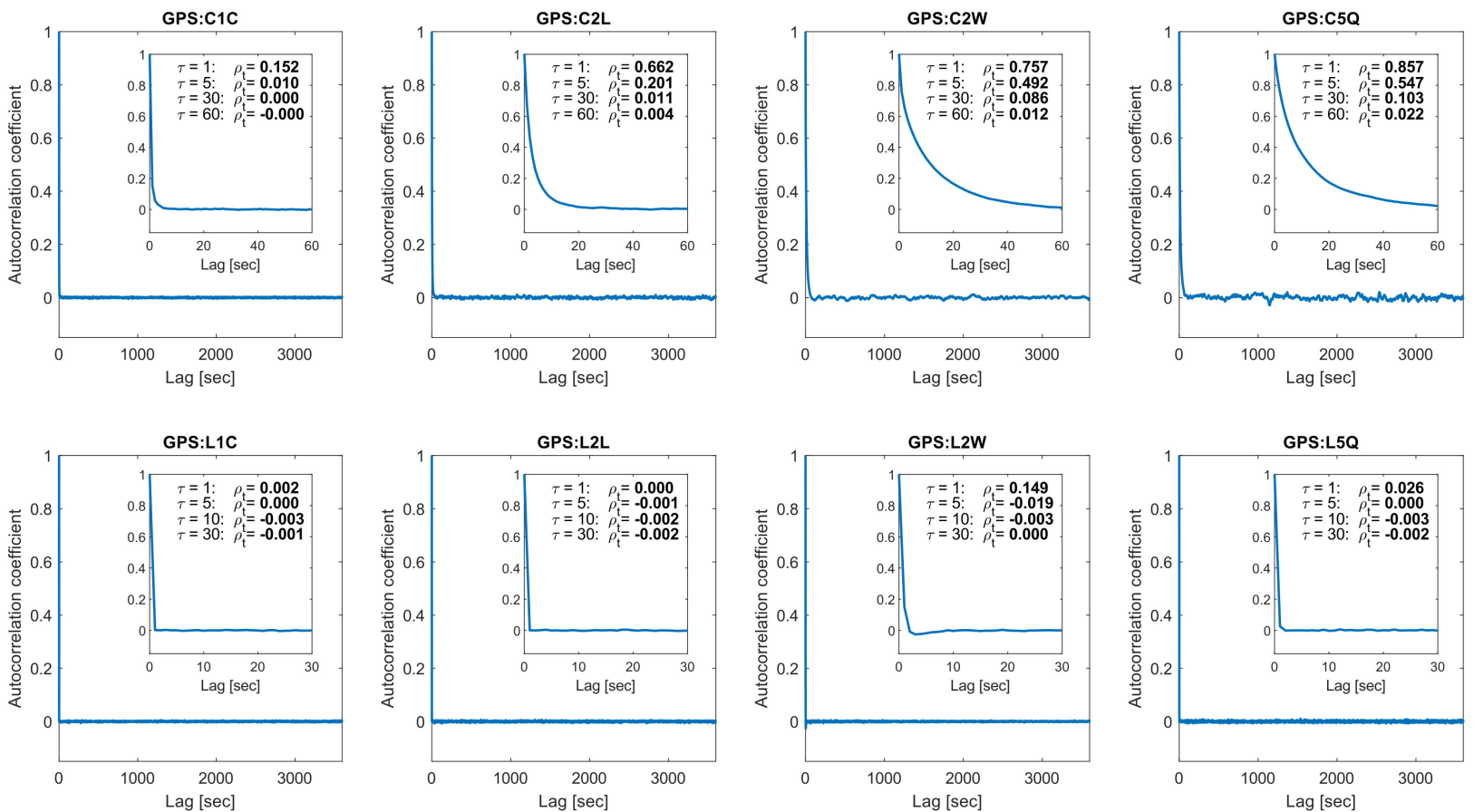

Figure 4. Sample autocorrelation coefficients for GPS observations (2019 DOY: 055). 

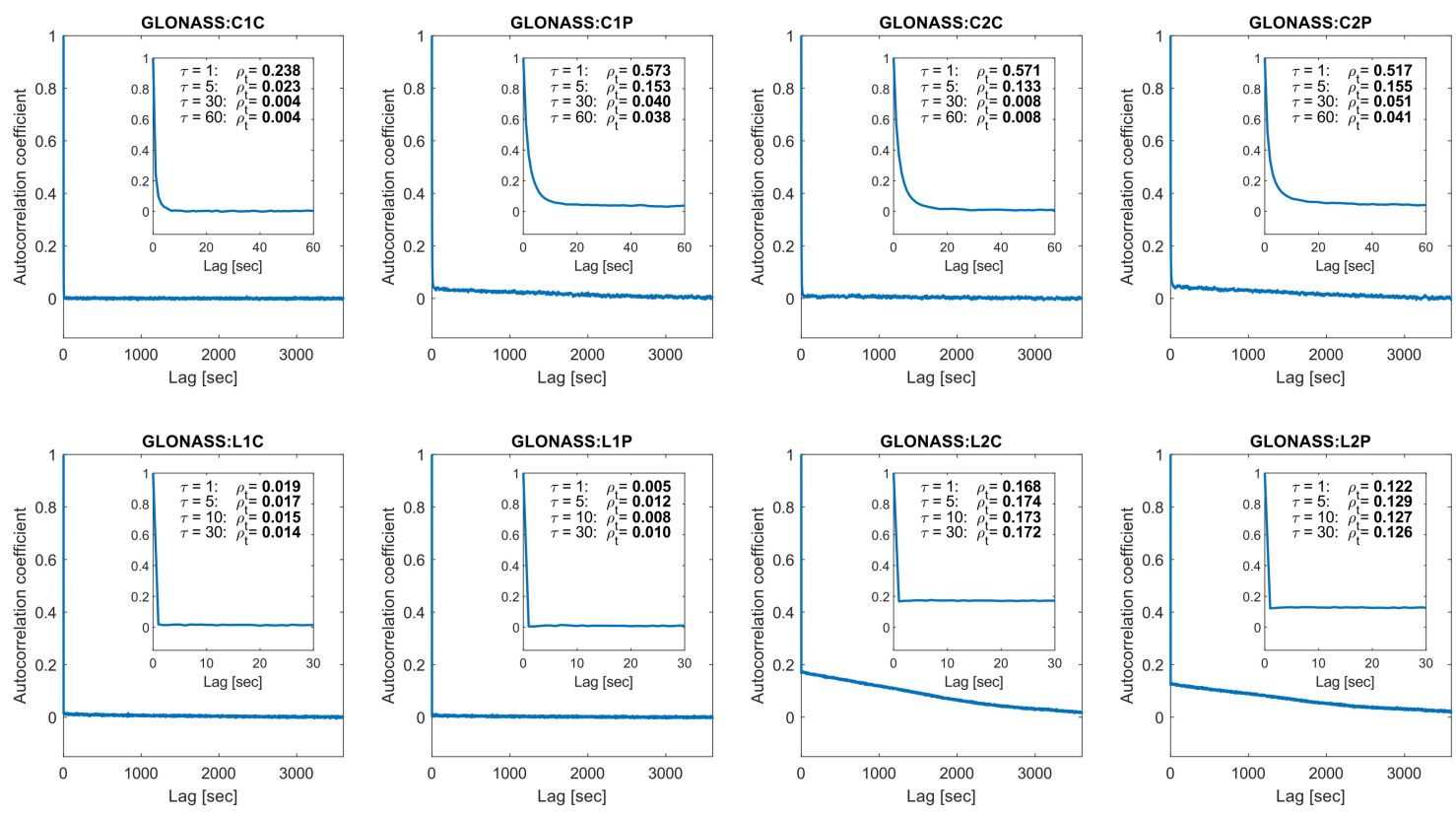

Figure 5. Sample autocorrelation coefficients for GLONASS observations (2019 DOY: 055).
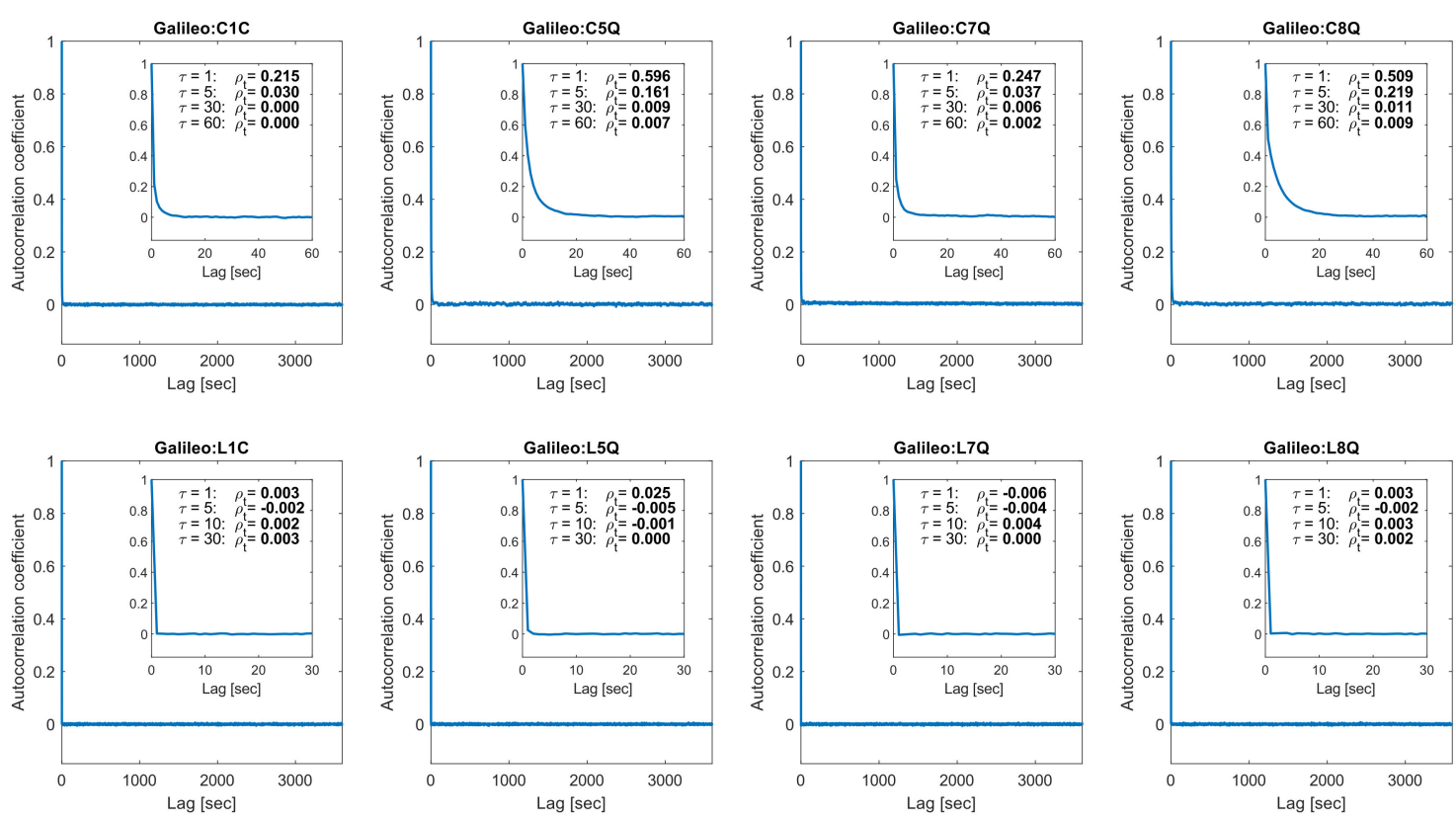

Figure 6. Sample autocorrelation coefficients for Galileo observations (2019 DOY: 055).

For all of the investigated code signals, it is easy to notice a high temporal correlation for a time lag equal to a few seconds. Especially for the GPS observations, the temporal correlation coefficient maintains a significant value that exceeds 0.2 for the time lag that is in the range of 10-20 s (except for C1C observations, for which the correlation time is only 2 s). For the GLONASS and Galileo systems, the obtained values of the time correlation are at a very similar level of 2-4 s for each code signal.

Only slightly higher correlation time values (up to $6 \mathrm{~s}$ ) are obtained for the Galileo C5Q and $\mathrm{C} 8 \mathrm{Q}$ observations. For the carrier phase measurements, the correlation time is much smaller and, in most cases, does not exceed $1 \mathrm{~s}$. Non-zero temporal correlation coefficient values for a time lag of at least $1 \mathrm{~s}$ can only be seen for the GPS L2W signal and GLONASS L2C and L2P signals. However, for the GPS L2W observations, it immediately drops to zero for $\tau=2 \mathrm{~s}$, while for the GLONASS observations, the decrease in the $\rho_{t}$ value is very 
slow and exceeds 2000 s, which may be due to the influence of the residual value of the frequency-dependent part of the IFB when using the FDMA technique for the GLONASS signals. In that case, the assumption IFB elimination using a homogenous receiver pair [55] may not be accurate for the L2 signals, but this requires additional confirmation.

The results for the weekly solution, which was determined as the average of the daily solutions, are presented in Table 3 in the form of an autocorrelation time lag, for which the temporal correlation coefficient drops below 0.2 . The time lag values are calculated as an average for all of the satellites for the analyzed signals while rejecting outliers with a confidence level of about $99 \%$. For the $1 \mathrm{~Hz}$ data, the smallest possible autocorrelation time lag is denoted as $\leq 1 \mathrm{~s}$.

Table 3. Autocorrelation time lag for the analysis of a GNSS system for $\rho_{t}<0.20$.

\begin{tabular}{cccc}
\hline \multirow{2}{*}{$\begin{array}{c}\text { System/ } \\
\text { Observation Type }\end{array}$} & \multicolumn{2}{c}{ Time Lag [sec] } \\
\cline { 3 - 4 } & $1 \mathrm{C}$ & Code & Phase \\
\hline \multirow{3}{*}{ GPS } & $2 \mathrm{~L}$ & $\leq 1$ & $\leq 1$ \\
& $2 \mathrm{~W}$ & 5 & $\leq 1$ \\
& $5 \mathrm{Q}$ & 18 & $\leq 1$ \\
& $1 \mathrm{C}$ & 17 & $\leq 1$ \\
\hline \multirow{3}{*}{ GLONASS } & $1 \mathrm{P}$ & 2 & $\leq 1$ \\
& $2 \mathrm{C}$ & 4 & $\leq 1$ \\
& $2 \mathrm{P}$ & 4 & $\leq 1$ \\
\hline \multirow{6}{*}{ Galileo } & $1 \mathrm{C}$ & 4 & $\leq 1$ \\
& $5 \mathrm{Q}$ & 2 & $\leq 1$ \\
& $7 \mathrm{Q}$ & 5 & $\leq 1$ \\
& $8 \mathrm{Q}$ & 2 & $\leq 1$ \\
\hline
\end{tabular}

Figure 7 shows the corresponding autocorrelation time lag results for a weekly solution in the form of a box plot. As for the carrier phase observations, a constant value of $\tau=1 \mathrm{~s}$ was obtained; in the graph, only the summary for the code observations is presented.

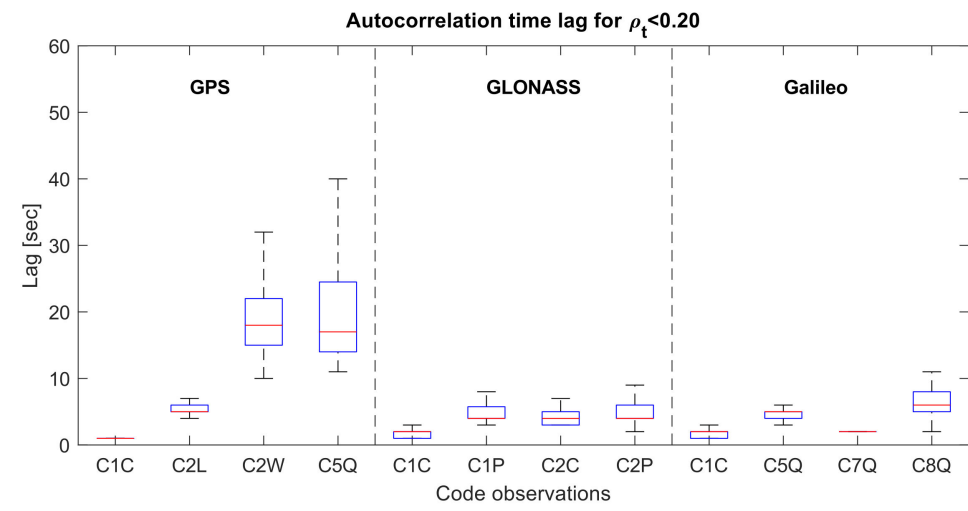

Figure 7. Autocorrelation time lag for code observations (weekly solution).

The obtained results of the autocorrelation time for the code observations for the adopted threshold $\rho_{t}<0.20$ show significant differences in the temporal correlation of the GNSS measurement noise. The GPS C2W and C5Q observations show the highest temporal correlation, with an average time lag of $17-18 \mathrm{~s}$ and spread reaching $40 \mathrm{~s}$. The lowest temporal correlation values and their highest repeatability were obtained for the GPS C1C and Galileo C7Q observations. The presented results lead to the conclusion that a double-differenced GNSS observation time series for a $1 \mathrm{~Hz}$ measurement rate can only be treated as not being correlated to time for carrier phase observations. For code observations, such an assumption can be made for observations with an interval of more 
than 20 s. Otherwise, for data with a higher measurement interval, correct data processing requires the observation time correlation to be considered in the stochastic model.

\subsection{Spectral Analysis}

Spectral analysis was performed for each satellite arc separately during the analyzed week. As an example of the results, the L-S periodograms for the GPS PRN09 ( $\operatorname{arc} 3$ ), GLONASS PRN21 (arc 14) and Galileo PRN19 (arc 5) satellites are presented in Figures 8-10. In our calculations, all of the available signals (Table 4) were analyzed separately for all of the satellites in the constellations. For all of the analyzed satellite signals, there is a noticeable change in the noise characteristic (power spectrum slope) around the frequency of $0.001 \mathrm{~Hz}$, regardless of the GNSS system. For this reason, the spectral index k was calculated for the part of the spectrum that was in the range $0.001 \mathrm{~Hz}-0.5 \mathrm{~Hz}$. The spectral index was determined by the linear regression of the L-S power spectrum after frequency and power logarithmization. The fitted line corresponding to the noise type is plotted in orange in Figures 8-10.

Table 4. Spectral index statistics for analyzed GNSS systems.

\begin{tabular}{ccccccc}
\hline \multirow{2}{*}{$\begin{array}{c}\text { System/ } \\
\text { Observation Type }\end{array}$} & \multirow{2}{*}{$\begin{array}{c}\text { Number } \\
\text { of Arcs }\end{array}$} & Median & std dev & Median & std dev \\
\cline { 4 - 7 } & 1C & 429 & -0.2 & 0.12 & 0.0 & 0.03 \\
\multirow{2}{*}{ GPS } & 2L & 242 & -1.0 & 0.12 & 0.0 & 0.03 \\
& 2W & 401 & -1.0 & 0.19 & -0.2 & 0.04 \\
& 5Q & 151 & -1.3 & 0.14 & 0.0 & 0.04 \\
GLONASS & 1C & 321 & -0.3 & 0.11 & 0.0 & 0.02 \\
& 1P & 317 & -0.8 & 0.13 & 0.0 & 0.02 \\
& 2C & 321 & -0.8 & 0.16 & 0.0 & 0.03 \\
Galileo & 2P & 321 & -0.7 & 0.19 & 0.0 & 0.03 \\
& $1 \mathrm{C}$ & 268 & -0.3 & 0.11 & 0.0 & 0.02 \\
& 5Q & 268 & -0.9 & 0.14 & 0.0 & 0.02 \\
& 7Q & 268 & -0.3 & 0.18 & 0.0 & 0.02 \\
\hline
\end{tabular}
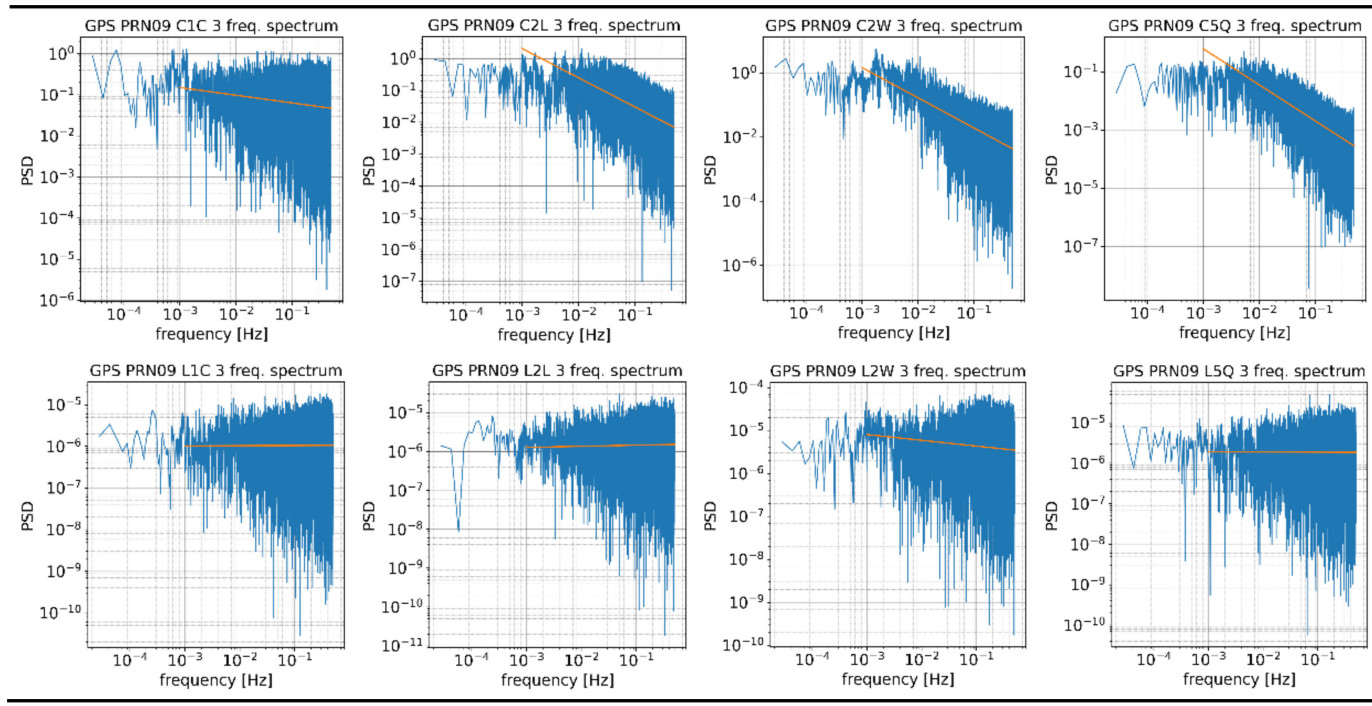

Figure 8. Lomb-Scargle periodograms for the GPS PRN09 satellite. Orange lines represent the line fitted in the part of the spectrum in the range of $0.001-0.5 \mathrm{~Hz}$. The slope of the line represents the spectral index value. 


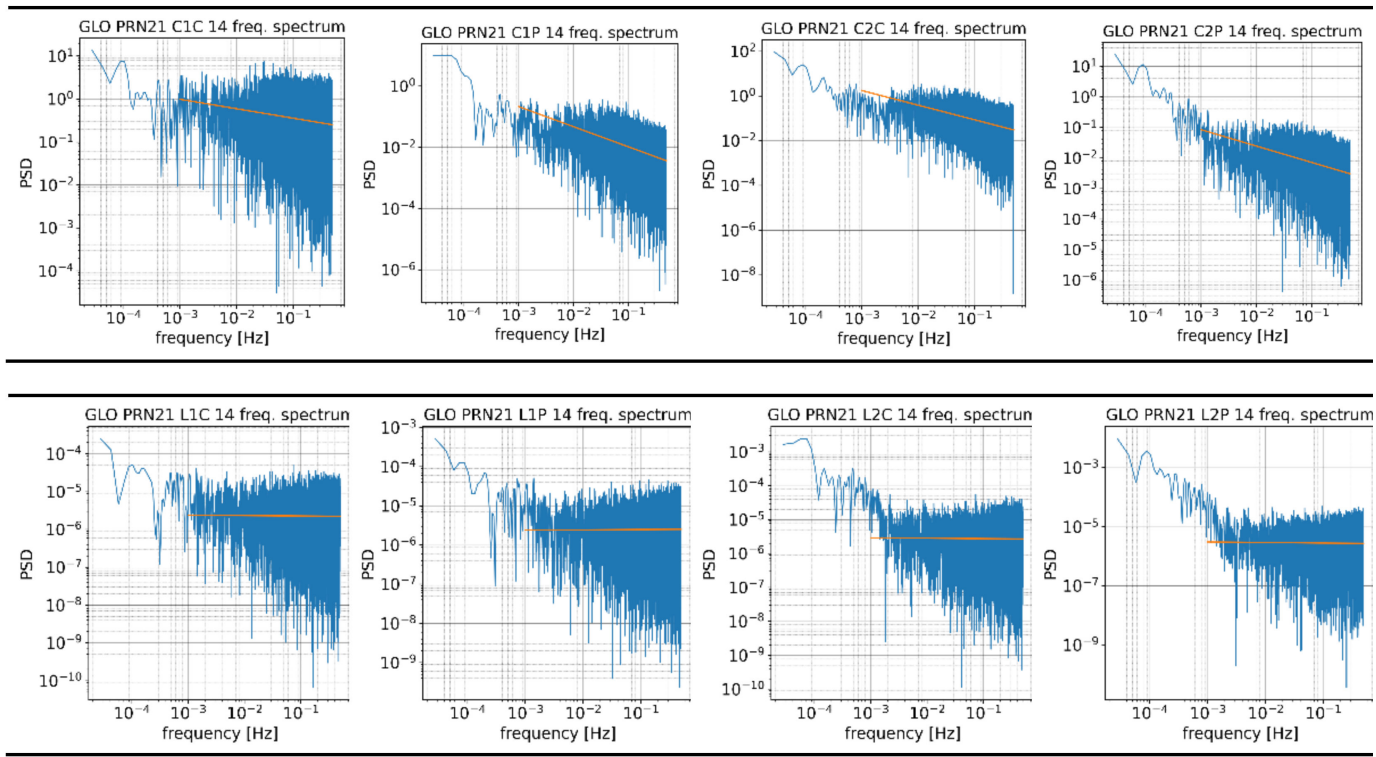

Figure 9. Lomb-Scargle periodograms for the GLONASS PRN21 satellite. Orange lines represent the line fitted in the part of the spectrum in the of range 0.001-0.5 Hz. The slope of the line represents the spectral index value.
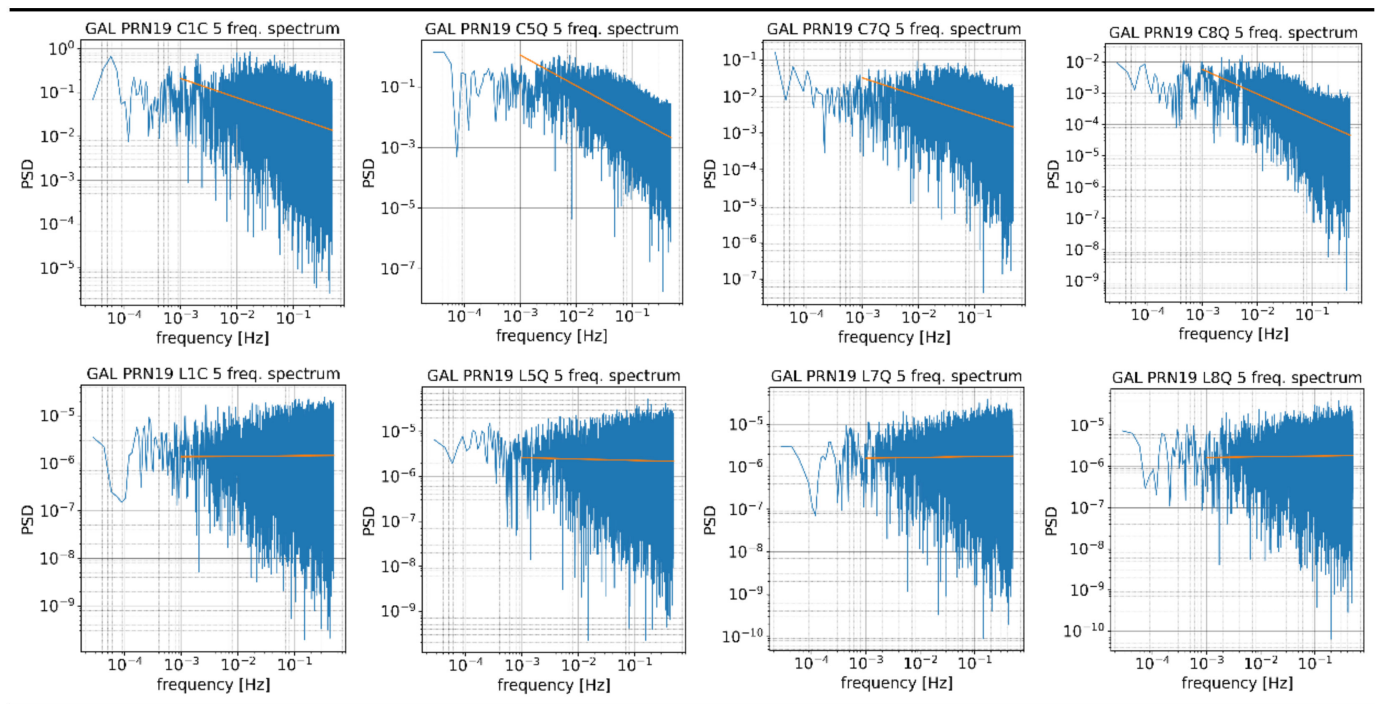

Figure 10. Lomb-Scargle periodograms for Galileo PRN19 satellite. Orange lines represent the line fitted in the part of the spectrum in the range of $0.001-0.5 \mathrm{~Hz}$. The slope of the line represents the spectral index value.

The spectral analysis examples presented in Figure 8 for GPS satellite PRN09 show that for all of the phase observations (L1C, L2L, L2W, and L5C), there is only white noise $(\mathrm{k}=0)$ presented over the entire frequency range studied. The code observations C2L, C2W, and $C 5 \mathrm{Q}$ show a clear change in the nature of the noise- the slope of the L-S spectrum-for frequencies above $10^{-2} \mathrm{~Hz}$. For frequencies below $10^{-2} \mathrm{~Hz}$, the spectral index is $\mathrm{k}=0$ (white noise), above $\mathrm{k}=-1$, which corresponds to flicker noise. On the other hand, in the C1C signal, fractional white noise is visible $(-1<\mathrm{k}<0)$.

As shown in the example for the GLO PRN21 satellite (Figure 9), in the case of the GLONASS satellites, all of the code observations (C1C, C1P, C2C, C2P) are characterized by the presence of flicker noise in the entire range of the tested frequencies. In the phase observations, white noise is present at frequencies above $10^{-3} \mathrm{~Hz}$, similar to the GPS 
observations. However, for frequency components lower than $10^{-3} \mathrm{~Hz}$, the noise is closer to flicker noise.

The code and phase observations of the Galileo system (the example of the GAL PRN19 satellite in Figure 10) exhibit the same type of noise as the GPS satellites. The code observations show flicker noise for frequencies above $10^{-2} \mathrm{~Hz}$, and the phase signals only show white noise.

Figure 11 and Table 4 show a statistical summary of the spectral index $k$ for the double differences of the code and phase observations for all of the GNSS signals analyzed. There is a clear similarity in the nature of the noise in the different types of observations.
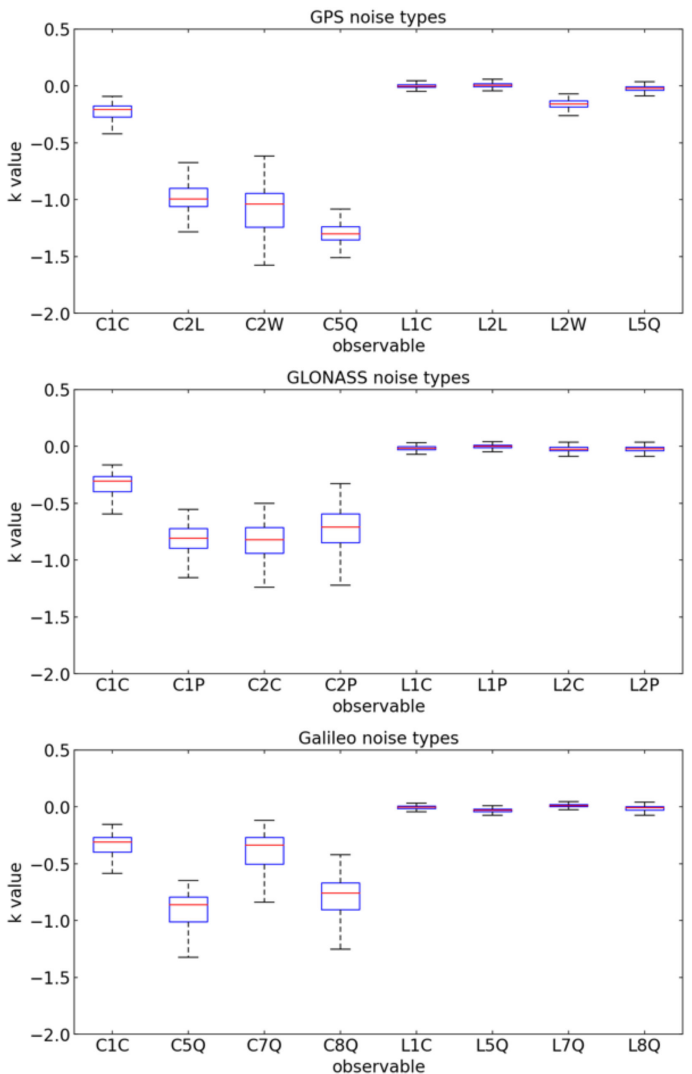

Figure 11. Spectral index for double differences of observations.

In the code observations, the noise has characteristics of flicker noise, except for the C1C observations for all of the GNSS systems and the C7Q signal of the Galileo system. In contrast, white noise is present in the double difference phase observations for all of the GNSS systems that were analyzed.

\subsection{Allan Variance}

Figures 12-14 show the MDEV calculated for each GPS, GLONASS, and Galileo satellite signal, respectively. The $z$-axis is the MDEV in seconds, the $x$-axis is averaging time $(T)$ in seconds, and the $y$-axis represents the satellites used in the evaluation. To make figure interpretation easier for the reader, the z-axis scale is the same for all of the images. 


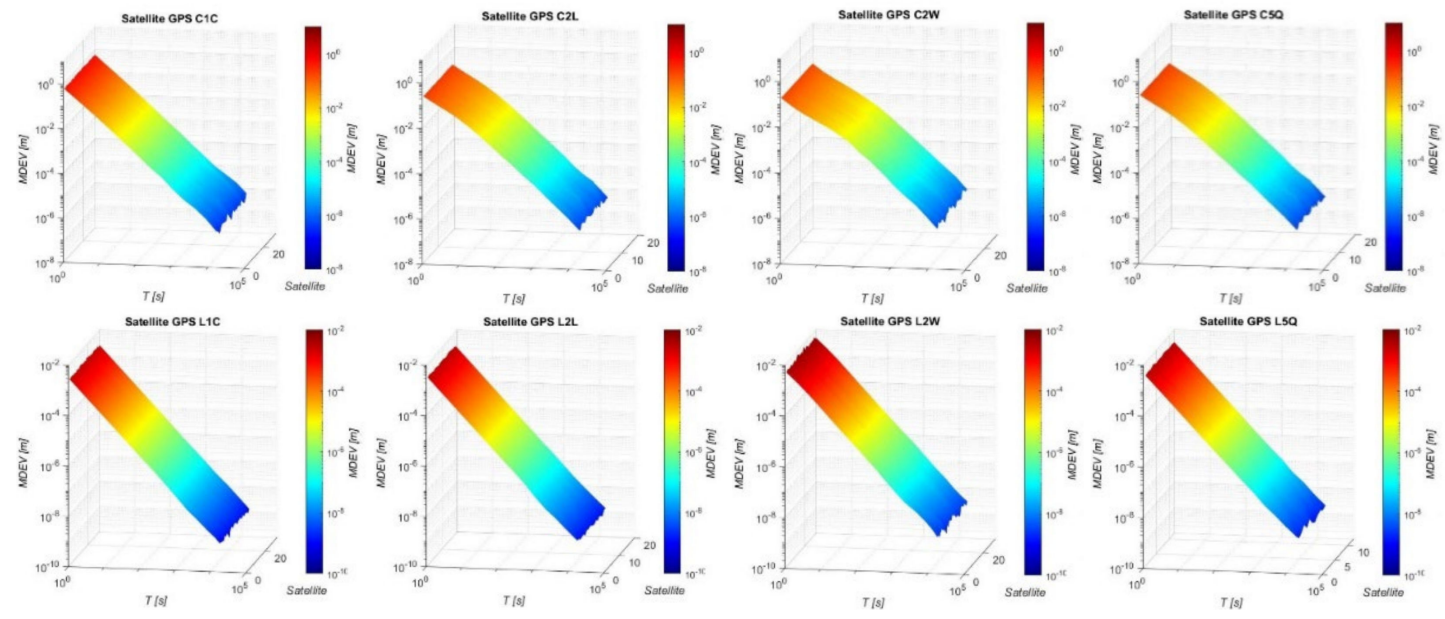

Figure 12. MDEV of the analyzed observation type for GPS satellites.
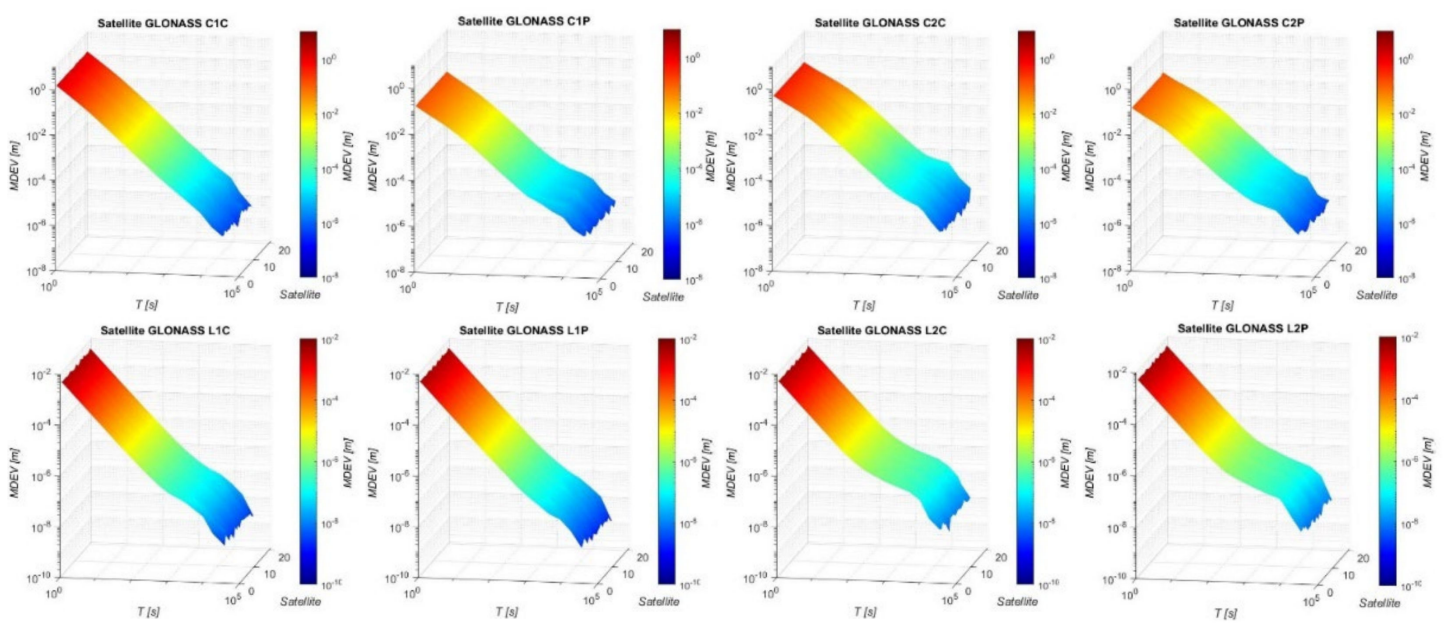

Figure 13. MDEV of the analyzed observation type for GLONASS satellites.
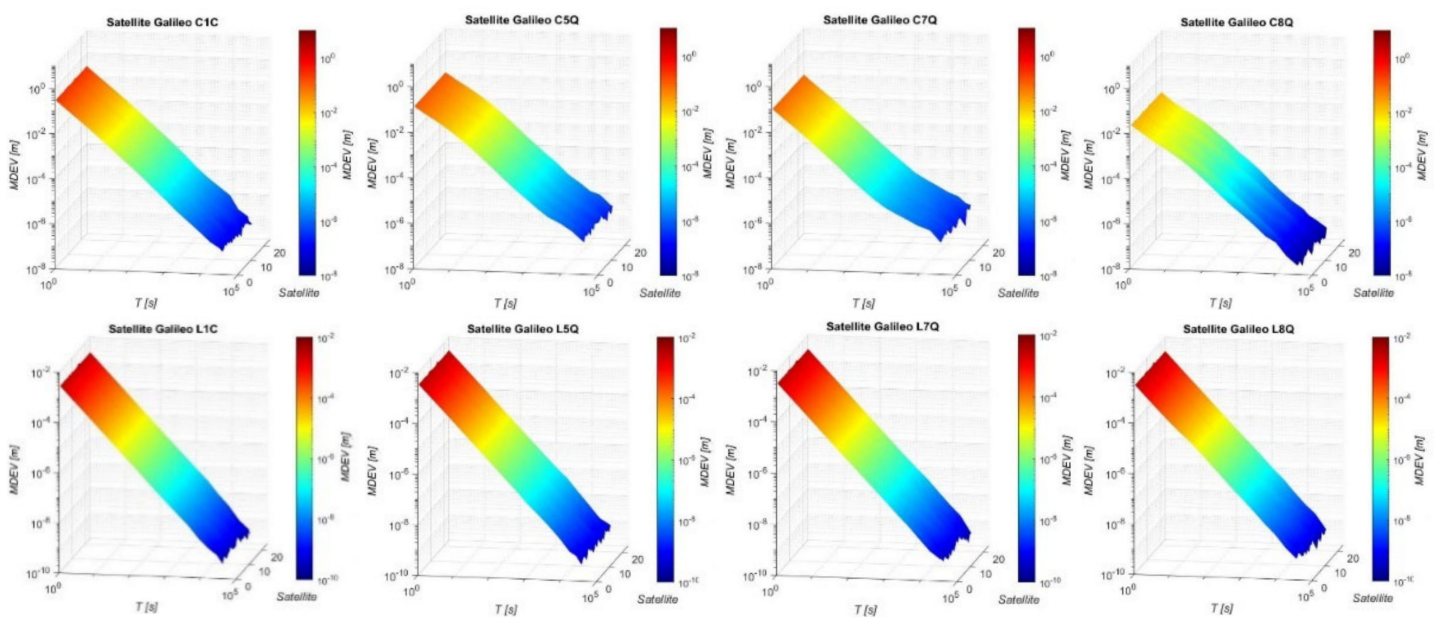

Figure 14. MDEV of the analyzed observation type for Galileo satellites.

Figure 12 shows the MDEV of the whole GPS segment divided by the signal type. The first row has the code signals, and the second row has the phase signals. The magnitudes for $\mathrm{C} 1 \mathrm{C}, \mathrm{C} 2 \mathrm{~L} \mathrm{C} 2 \mathrm{~W}$, and $\mathrm{C} 5 \mathrm{Q}$ are very similar and cover ranges between $10^{0} \mathrm{~s}$ and $10^{-7} \mathrm{~s}$. 
In the case of the phase signals, the MDEV ranges for each signal are between the ranges from $10^{-2} \mathrm{~s}$ to $10^{-9} \mathrm{~s}$, which is two orders of magnitude more accurate in relation to the code signals.

Figure 13 shows the MDEV of the GLONASS signals divided by the type. The magnitudes for $\mathrm{C} 1 \mathrm{C}$ and $\mathrm{C} 2 \mathrm{C}$ are similar and cover ranges between $10^{0} \mathrm{~s}$ to $10^{-7} \mathrm{~s}$, while for $\mathrm{C} 1 \mathrm{P}$ and $\mathrm{C} 2 \mathrm{C}$, the ranges vary between $10^{-1} \mathrm{~s}$ and $10^{-6} \mathrm{~s}$. In the case of the phase signals, the MDEV ranges for each signal are between $10^{-2} \mathrm{~s}$ and $10^{-8} \mathrm{~s}$. The slope of the graphs also differs from one signal to another and is consistent for each satellite. Such analyses are presented later in the text.

Unlike GPS and GLONASS, the Galileo code observations do not have the same range of data values (Figure 14). For the C1C, C5Q, and C7Q signals, the range is from $10^{-1} \mathrm{~s}$ to $10^{-9} \mathrm{~s}$. In contrast, the $\mathrm{C} 8 \mathrm{Q}$ signal is an order of magnitude more accurate and ranges from $10^{-2} \mathrm{~s}$ to $10^{-9} \mathrm{~s}$, which corresponds to the accuracy of the phase observations of the GPS and GLONASS signals. In the case of the Galileo phase observations, the stability is similar for each type of signal and ranges from $10^{-2} \mathrm{~s}$ to $10^{-10} \mathrm{~s}$, which is the most accurate among all of phase signals from the analyzed GNSS systems.

Figure 15 shows the averaged MDEV values for each signal type and system. The first row comprises mean code values, and the second comprises the phase values. Moreover, properly matched noise was added to the data on the chart in each graph. In the case of the code signals for the GPS and Galileo signals, the shortest averaging times $(\tau \leq 128 \mathrm{~s})$ are affected by the flicker PM $\left(\tau^{-1}\right)$, while the 1 white PM $\left(\tau^{-1.5}\right)$ is the noticed. The GLONASS code signals are also affected by the above two noise types, but the flicker PM characterizes the observations for $\tau \leq 16 \mathrm{~s}$, and white PM characterizes the others.
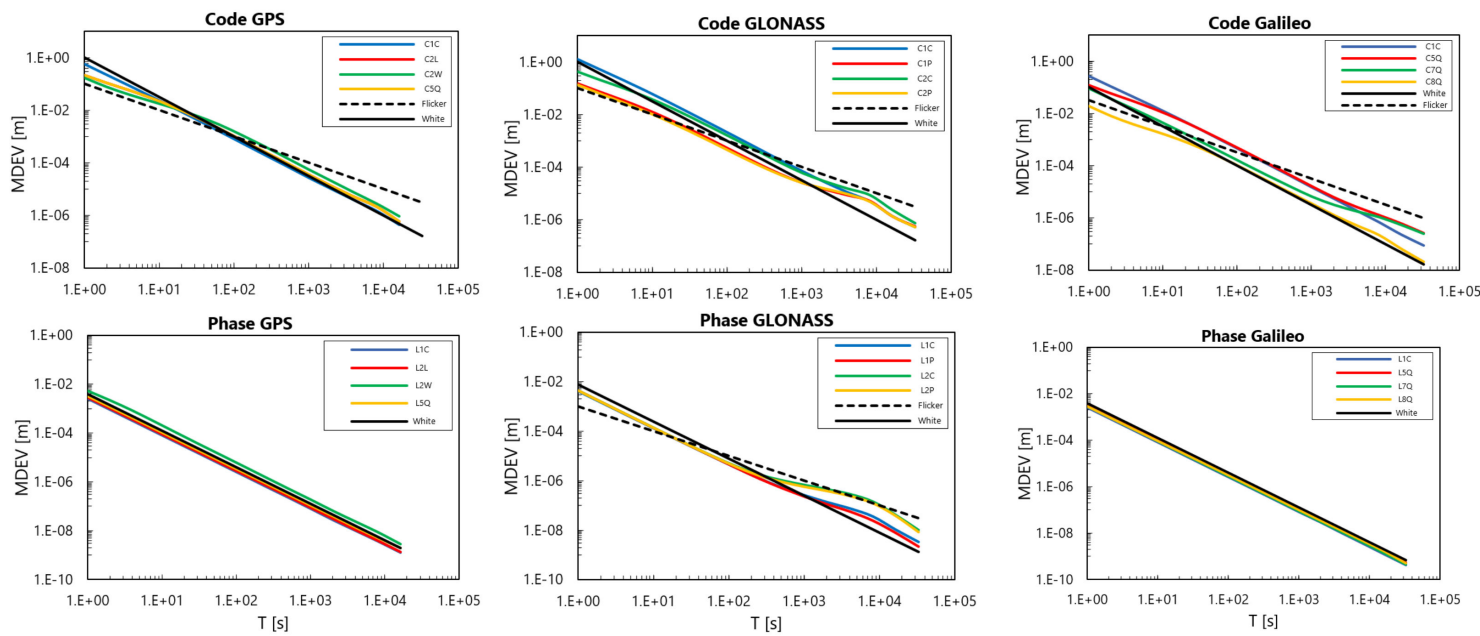

Figure 15. Averaged MDEV for each system along with the types of noise fitted to them.

In the case of the phase observations for the GPS and Galileo systems, all of the observation types are very consistent with each other, which shows high-quality and perfect reproduction of the white PM noise (Figure 15, 2nd row). In the case of the GLONASS system, the conclusions are the same as they are in the case of the code signals-for $\tau<64 \mathrm{~s}$ flicker PM, for the other, larger averaging times represents white PM. Additionally, none of the four types of GLONASS phase observations are consistent with each other-this is not reflected in any of the graphs.

\section{Discussion and Conclusions}

This contribution presents research on the noise characteristics of double-differenced GNSS measurements. Based on weekly observations from a zero-length baseline, a detailed analysis of the noise type was performed for the code and carrier phase measurements for the GPS, GLONASS, and Galileo systems. The use of the autocorrelation function, spectral 
analysis using the L-S method, and a modified Allan deviation indicator made it possible to determine the type of noise and its parameters for individual systems and signals.

For the tested signals, significant differentiation of the noise level is visible: the GPS C5Q and Galileo C7Q and C8Q signals are characterized by the highest accuracy among the code observations, with the standard deviation not exceeding $\pm 10 \mathrm{~cm}$; the lowest accuracy was obtained for the GLONASS C1C and C2C observations, for which the standard deviations were $\pm 90 \mathrm{~cm}$ and $\pm 45 \mathrm{~cm}$, respectively. The noise level for the carrier phase observations was very similar for all of the signal types and is in the range of $\pm 1.5-3.5 \mathrm{~mm}$.

The ACF analysis showed significant differences in the characteristics of the analyzed signals. Code signals, particularly GPS C2W and C5Q signals, are characterized by a significant temporal correlation, unlike carrier phase signals. The presented results lead to the conclusion that the double-differenced GNSS observation time series for a $1 \mathrm{~Hz}$ measurement rate can only be treated not being related to time for carrier phase observations. For code observations, such an assumption can be made for observations with an interval of more than $20 \mathrm{~s}$.

Depending on the kind of observations and their type, one should notice that the signals and the corresponding noise types have different stabilities. In the case of code observations, all signals of the are consistent with each other and can be characterized depending on the averaging time as either flicker PM or white PM. In the case of the GPS and Galileo phase observations, they are all uniquely characterized by white PM. In the case of the GLONASS satellites-similar to the code observations-white PM or flicker PM are possible depending on the integration step.

It should be noted that as the presented research does not include analyses of the dependence of the noise level on the SNR, C/N0, satellite elevation, or receiver type, they could be the subject of further study.

Author Contributions: Conceptualization, D.P., J.K. and K.M.; methodology, D.P., J.K. and K.M.; software, D.P., J.K. and K.M.; validation, D.P., J.K. and K.M.; formal analysis, D.P., J.K. and K.M.; investigation, D.P., J.K. and K.M.; resources, D.P., J.K. and K.M.; data curation, D.P., J.K. and K.M.; writing-original draft preparation, D.P., J.K. and K.M.; writing-review and editing, D.P., J.K. and K.M.; visualization, D.P., J.K. and K.M.; supervision, D.P., J.K. and K.M.; project administration, D.P., J.K. and K.M.; funding acquisition, D.P., J.K. and K.M. Authors contribution: D.P. 40\%, J.K. 30\%, K.M. $30 \%$. All authors have read and agreed to the published version of the manuscript.

Funding: This work was funded by the National Science Centre, Poland: Project No. 2016/23/D/ ST10/00498 and by the Initiative for Excellence-Research University grant at AGH University of Science and Technology; and under scientific research 16.16.150.545.

Institutional Review Board Statement: Not applicable.

Informed Consent Statement: Not applicable.

Data Availability Statement: Not applicable.

Conflicts of Interest: The authors declare no conflict of interest.

\section{References}

1. Borre, K.; Tiberius, C. Time Series Analysis of GPS Observables. In Proceedings of the 13th International Technical Meeting of the Satellite Division of The Institute of Navigation ION GP, Salt Lake City, UT, USA, 19-22 September 2000; pp. 1885-1894.

2. Zangenehnejad, F.; Gao, Y. GNSS smartphones positioning: Advances, challenges, opportunities, and future perspectives. Satell. Navig. 2021, 2, 24. [CrossRef] [PubMed]

3. Paziewski, J.; Sieradzki, R.; Baryla, R. Signal characterization and assessment of code GNSS positioning with low-power consumption smartphones. GPS Solut. 2019, 23, 98. [CrossRef]

4. Luo, Y.; Li, J.; Yu, C.; Xu, B.; Li, Y.; Hsu, L.T.; El-Sheimy, N. Research on Time-Correlated Errors Using Allan Variance in a Kalman Filter Applicable to Vector-Tracking-Based GNSS Software-Defined Receiver for Autonomous Ground Vehicle Navigation. Remote Sens. 2019, 11, 1026. [CrossRef]

5. Wang, D.; Dong, Y.; Li, Q.; Li, Z.; Wu, J. Using Allan variance to improve stochastic modeling for accurate GNSS/INS integrated navigation. GPS Solut. 2018, 22, 53. [CrossRef] 
6. Wang, J. Stochastic Assessment of the GPS Measurements for Precise Positioning. In Proceedings of the 11th International Technical Meeting of the Satellite Division of The Institute of Navigation (ION GPS 1998), Nashville, TN, USA, 15-18 September 1998; pp. 81-89.

7. Howind, J.; Kutterer, H.; Heck, B. Impact of temporal correlations on GPS-derived relative point positions. J. Geod. 1999, 73, 246-258. [CrossRef]

8. Bona, P. Precision, Cross Correlation, and Time Correlation of GPS Phase and Code Observations. GPS Solut. 2000, 4, 3-13. [CrossRef]

9. Teunissen, P.J.G.; Jonkman, N.F.; Tiberius, C.C.J.M. Weighting GPS Dual Frequency Observations: Bearing the Cross of CrossCorrelation. GPS Solut. 1998, 2, 28-37. [CrossRef]

10. Schön, S.; Brunner, F.K. A proposal for modelling physical correlations of GPS phase observations. J. Geod. 2008, 82, 601-612. [CrossRef]

11. Foucras, M.; Leclère, J.; Botteron, C.; Julien, O.; Macabiau, C.; Farine, P.A.; Ekambi, B. Study on the cross-correlation of GNSS signals and typical approximations. GPS Solut. 2017, 21, 293-306. [CrossRef]

12. Hou, P.; Zhang, B.; Yuan, Y. Analysis of the stochastic characteristics of GPS/BDS/Galileo multi-frequency observables with different types of receivers. J. Spat. Sci. 2021, 66, 49-73. [CrossRef]

13. Prochniewicz, D.; Wezka, K.; Kozuchowska, J. Empirical stochastic model of multi-GNSS measurements. Sensors 2021, $21,4566$. [CrossRef]

14. Eueler, H.J.; Goad, C.C. On optimal filtering of GPS dual frequency observations without using orbit information. Bull. Géodésique 1991, 65, 130-143. [CrossRef]

15. Xiang Jin, X.; de Jong, C.D. Relationship between Satellite Elevation and Precision of GPS Code Observations. J. Navig. 1996, 49, 253-265. [CrossRef]

16. Li, B. Stochastic modeling of triple-frequency BeiDou signals: Estimation, assessment and impact analysis. J. Geod. 2016, 90, 593-610. [CrossRef]

17. Gianniou, M.; Groten, E. An Advanced Real-Time Algorithm for Code and Phase DGPS. In Proceedings of the DSNS'96 Conference, St. Petersburg, Russia, 20-24 May 1996.

18. Luo, X.; Mayer, M.; Heck, B. Improving the Stochastic Model of GNSS Observations by Means of SNR-based Weighting. In Observing our Changing Earth; Springer: Berlin/Heidelberg, Germany, 2009; pp. 725-734.

19. Talbot, N. Optimal weighting of GPS carrier phase observations based on the signal-to-noise ratio. In Proceedings of the International Symposia on Global Positioning Systems, Queensland, Australia, 17-19 October 1988.

20. Hartinger, H.; Brunner, F.K. Variances of GPS Phase Observations: The SIGMA- $\varepsilon$ Model. GPS Solut. 1999, 2, 35-43. [CrossRef]

21. Andreas Wieser, F.K.B. An extended weight model for GPS phase observations. Earth Planets Sp. 2000, 52, 777-782. [CrossRef]

22. Aquino, M.; Monico, J.F.G.; Dodson, A.H.; Marques, H.; De Franceschi, G.; Alfonsi, L.; Romano, V.; Andreotti, M. Improving the GNSS positioning stochastic model in the presence of ionospheric scintillation. J. Geod. 2009, 83, 953-966. [CrossRef]

23. da Silva, H.A.; de Oliveira Camargo, P.; Galera Monico, J.F.; Aquino, M.; Marques, H.A.; De Franceschi, G.; Dodson, A. Stochastic modelling considering ionospheric scintillation effects on GNSS relative and point positioning. Adv. Sp. Res. 2010, 45, 1113-1121. [CrossRef]

24. Seepersad, G.; Bisnath, S. Reduction of precise point positioning convergence period. In Proceedings of the 25th International Technical Meeting of the Satellite Division of the Institute of Navigation 2012, ION GNSS 2012, Nashville, TN, USA, 17-21 September 2012; Volume 5, pp. 3742-3752.

25. Luo, X. GPS Stochastic Modelling-Signal Quality Measures and ARMA Processes; Springer Science \& Business Media: Berlin/Heidelberg, Germany, 2013.

26. El-Rabbany, A. The Effect of Physical Correlations on the Ambiguity Resolution and Accuracy Estimation in GPS Differential Positioning; University of New Brunswick: Fredericton, NB, Canada, 1994.

27. Tiberius, C.; Jonkman, N.; Kenselaar, F. The stochastics of GPS observables. GPS World 1999, 10, 49-54.

28. Li, B.; Shen, Y.; Xu, P. Assessment of stochastic models for GPS measurements with different types of receivers. Sci. Bull. 2008, 53, 3219-3225. [CrossRef]

29. Pilgram, B.; Kaplan, D.T. A comparison of estimators for noise. Phys. D Nonlinear Phenom. 1998, 114, 108-122. [CrossRef]

30. Levitin, D.J.; Chordia, P.; Menon, V. Musical rhythm spectra from Bach to Joplin obey a 1/f power law. Proc. Natl. Acad. Sci. USA 2012, 109, 3716-3720. [CrossRef] [PubMed]

31. Gabaix, X. Power Laws in Economics and Finance; Annual Review of Economics: Cambridge, MA, USA, 2008.

32. Bos, M.S.; Fernandes, R.M.S.; Williams, S.D.P.; Bastos, L. Fast error analysis of continuous GPS observations. J. Geod. 2008, 82, 157-166. [CrossRef]

33. Chen, X.; Peng, C.; Huan, H.; Nian, F.; Yang, B. Measuring the Power Law Phase Noise of an RF Oscillator with a Novel Indirect Quantitative Scheme. Electronics 2019, 8, 767. [CrossRef]

34. Vaughan, S. A simple test for periodic signals in red noise. Astron. Astrophys. 2005, 431, 391-403. [CrossRef]

35. Williams, S.D.P.; Bock, Y.; Fang, P.; Jamason, P.; Nikolaidis, R.M. Error analysis of continuous GPS position time series. J. Geophys. Res. 2004, 109, B03412. [CrossRef]

36. Williams, S.D.P. CATS: GPS coordinate time series analysis software. GPS Solut. 2008, 12, 147-153. [CrossRef]

37. Lomb, N.R. Least-squares frequency analysis of unequally spaced data. Astrophys. Space Sci. 1976, 39, 447-462. [CrossRef] 
38. Scargle, J.D. Studies in astronomical time series analysis. II-Statistical aspects of spectral analysis of unevenly spaced data. Astrophys. J. 1982, 263, 835. [CrossRef]

39. Allan, D.W. Statistics of atomic frequency standards. Proc. IEEE 1966, 54, 221-230. [CrossRef]

40. Hackl, M.; Malservisi, R.; Hugentobler, U.; Jiang, Y. Velocity covariance in the presence of anisotropic time correlated noise and transient events in GPS time series. J. Geodyn. 2013, 72, 36-45. [CrossRef]

41. Malkin, Z. Application of the Allan Variance to Time Series Analysis in Astrometry and Geodesy: A Review. IEEE Trans. Ultrason. Ferroelectr. Freq. Control 2016, 63, 582-589. [CrossRef]

42. Hefty, J.; Igondová, M.; Hrcka, M. Contribution of Gps Permanent Stations in Central Europe to Regional Geo-Kinematical Investigations. Acta Geodyn. Geomater. 2005, 2, 75-86.

43. Le Bail, K. Etude Statistique de la Stabileté des Stations de Géodésie Spatiale, Application à DORIS; Observatoire de Paris: Paris, France, 2004.

44. Howe, D.A.; Allan, D.U.; Barnes, J.A. Properties of Signal Sources and Measurement Methods. In Proceedings of the Thirty Fifth Annual Frequency Control Symposium, Philadelphia, PA, USA, 27-29 May 1981; pp. 669-716.

45. Le Bail, K. Estimating the noise in space-geodetic positioning: The case of DORIS. J. Geod. 2006, 80, 541-565. [CrossRef]

46. Khelifa, S.; Kahlouche, S.; Belbachir, M.F. Analysis of position time series of GPS-DORIS co-located stations. Int. J. Appl. Earth Obs. Geoinf. 2012, 20, 67-76. [CrossRef]

47. de Bakker, P.F.; van der Marel, H.; Tiberius, C.C.J.M. Geometry-free undifferenced, single and double differenced analysis of single frequency GPS, EGNOS and GIOVE-A/B measurements. GPS Solut. 2009, 13, 305-314. [CrossRef]

48. Gourevitch, S. Innovation: Measuring GPS receiver performance-A new approach. GPS World 1996, 7, 56-62.

49. Amiri-Simkooei, A.R.; Tiberius, C.C.J.M.; Teunissen, P.J.G. Assessment of noise in GPS coordinate time series: Methodology and results. J. Geophys. Res. Solid Earth 2007, 112, 1-19. [CrossRef]

50. Petovello, M.G.; Lachapelle, G. Estimation of Clock Stability Using GPS. GPS Solut. 2000, 4, 21-33. [CrossRef]

51. Jia, X.; Zeng, T.; Ruan, R.; Mao, Y.; Xiao, G. Atomic clock performance assessment of BeiDou-3 basic system with the noise analysis of orbit determination and time synchronization. Remote Sens. 2019, 11, 2895. [CrossRef]

52. Wang, G.; Liu, L.; Xu, A.; Pan, F.; Cai, Z.; Xiao, S.; Tu, Y.; Li, Z. On the capabilities of the inaction method for extracting the periodic components from GPS clock data. GPS Solut. 2018, 22, 1-14. [CrossRef]

53. Riley, W.J. Handbook of Frequency Stability Analysis; National Institute of Standards and Technology: Gaithersburg, MD, USA, 2008; Volume 31, ISBN 3019753058.

54. IGS RINEX WG, RTCM-SC104. RINEX-The Receiver Independent EXchange Format. Version 3.04. 2018. Available online: http:/ /acc.igs.org/misc/rinex304.pdf (accessed on 1 December 2021).

55. Al-shaery, A.; Lim, S.; Rizos, C. Challenges of Seamless Multi-GNSS. In Proceedings of the IAIN Congress, Cairo, Egypt, 1-3 October 2012; pp. 1-20. 